\title{
Communication
}

\section{Nuclear and Mitochondrial Data on Trichuris from Macaca fuscata Support Evidence of Host Specificity}

\author{
Serena Cavallero ${ }^{1, *(1)}$, Margherita Montalbano Di Filippo ${ }^{2,3}$, Silvia Rondón ${ }^{1}{ }^{(\mathbb{D}}$, Claudio De Liberato ${ }^{4}$, \\ Stefano D'Amelio ${ }^{1} \mathbb{D}$, Klaus G. Friedrich ${ }^{5}$ and Federica Berrilli ${ }^{2} \mathbb{D}$ \\ 1 Department of Public Health and Infectious Diseases, Sapienza University of Rome, Piazzale Aldo Moro 5, \\ 00185 Rome, Italy; silvia.rondon@uniroma1.it (S.R.); stefano.damelio@uniroma1.it (S.D.) \\ 2 Department of Clinical Sciences and Translational Medicine, University of Rome Tor Vergata, \\ Via Montpellier 1, 00133 Rome, Italy; montalbano.margherita89@gmail.com (M.M.D.F.); \\ berrilli@uniroma2.it (F.B.) \\ 3 Istituto Superiore di Sanità-Viale Regina Elena 299, 00161 Rome, Italy \\ 4 Istituto Zooprofilattico Sperimentale del Lazio e della Toscana "M. Aleandri", Via Appia Nuova 1411, \\ 00178 Rome, Italy; claudio.deliberato@izslt.it \\ 5 Fondazione Bioparco di Roma, Piazzale del Giardino Zoologico 1, 00197 Rome, Italy; \\ klaus.friedrich@bioparco.it \\ * Correspondence: serena.cavallero@uniroma1.it
}

check for updates

Citation: Cavallero, S.; Montalbano Di Filippo, M.;

Rondón, S.; Liberato, C.D.;

D'Amelio, S.; Friedrich, K.G.;

Berrilli, F. Nuclear and Mitochondrial Data on Trichuris from Macaca fuscata Support Evidence of Host Specificity. Life 2021, 11, 18. https:/ / doi.org/ 10.3390/life11010018

Received: 27 November 2020 Accepted: 25 December 2020 Published: 31 December 2020

Publisher's Note: MDPI stays neutral with regard to jurisdictional clai$\mathrm{ms}$ in published maps and institutional affiliations.

Copyright: $\odot 2020$ by the authors. Licensee MDPI, Basel, Switzerland. This article is an open access article distributed under the terms and conditions of the Creative Commons Attribution (CC BY) license (https:// creativecommons.org/licenses/by/ $4.0 /)$.

\begin{abstract}
Whipworms are parasitic intestinal nematodes infecting mammals, and traditionally humans and other primates that have so far been considered infected by Trichuris trichiura. Recent molecular studies report a more complex scenario suggesting the presence of a species complex with several Trichuris taxa specifically infecting only one primate species as well as taxa able to infect a range of primate species. The systematics of the group is important for taxonomic inference, to estimate the relative zoonotic potential, and for conservation purposes. In fact, captive animals living in zoological gardens are usually infected by persistent monoxenous intestinal parasites. Here, two Japanese macaques living in the Bioparco Zoological Garden of Rome were found infected by Trichuris sp. Nematodes were characterized at the molecular level using nuclear (btub and 18S) and mitochondrial (16S and cytb) markers and then compared to Trichuris collected previously in the same location, and to other Trichuris infecting primates. Evidences from mitochondrial and nuclear markers allowed for the identification of Trichuris sp. specific to Macaca fuscata. Results obtained here also described a uniform taxonomic unit of Trichuris, separated but closely related to Trichuris trichiura, thus, emphasizing its zoonotic potential for workers and visitors.
\end{abstract}

Keywords: Trichuris; Macaca fuscata; captive animals; zoonotic risk

\section{Introduction}

Gastrointestinal parasites infecting animals in captivity include zoonotic species and may raise public health concerns. In addition, monoxenous gastrointestinal protozoa and nematodes may cause diarrhea as a least concern or endanger non-human primate (NHP) species [1], contributing to morbidity and mortality [2]. Among the others, Trichuris spp. infect captive animals worldwide $[3,4]$ and they are reported as the most prevalent species in primates living in zoological gardens in China [5].

Nematodes of the genus Trichuris are intestinal parasites infecting mammals including humans, with a significant degree of host affiliation [6]. Human trichuriasis, caused by the species Trichuris trichiura, is one of three major soil-transmitted helminthiases, affecting around 800 million people worldwide [7]. Trichuris trichiura was proposed to be a complex of cryptic species able to infect human and NHPs living in the wild and in captivity [8].

Trichuris sp. worms were found also in Italy, infecting colonies of the crab-eating macaque (Macaca fascicularis) used for research [9], as well as the Japanese macaque (Macaca fuscata) living in the Bioparco Zoological Garden of Rome [10,11]. These infections can 
be very persistent, due to the high environmental resistance of eggs and to the long life span of adults, therefore requiring specific treatment strategies and big economic efforts for their eradication from a colony of captive NHPs [12]. Additionally, the more recent animal welfare management approaches used in confined locations, as the setting of multiple species environments and of conditions resembling natural environments, may favor the spread and persistence of nematodes and the transmission within and among species [13]. Beside the threat for vulnerable or critically endangered animals hosted in zoological gardens, the occurrence of zoonotic parasites suggests the need for appropriate and sensitive techniques to control them and highlight the related health risks for handlers.

In this scenario, the relevance of a correct identification of these parasites is highlighted, in the attempt at defining their eventual zoonotic relevance. The present study is aimed to characterize at the molecular level Trichuris sp. from two Japanese macaques hosted in the Bioparco Zoological Garden of Rome, using nuclear (18S and beta-tubulin) and mitochondrial (16S and cytb) molecular markers. Considering the recurrent Trichuris infections in the Bioparco, we also compared the material collected here to previously analyzed Trichuris sp. from the same NHP species monitored over a decade, to estimate genetic polymorphism and phylogenetic relationship among the parasitic nematodes in the colony of Japanese macaques living in the Bioparco since the 1980s.

\section{Materials and Methods}

\subsection{Sample Collection and Molecular Methods}

Two adult Japanese macaques (Macaca fuscata) died at the Bioparco Zoological Garden of Rome (Italy) in January and in September of 2020. Animals were hosted in strict accordance with good animal practices and veterinary inspection procedures. The two animals belonged to a long lasting colony of Japanese macaques that were born at the Bioparco. During necropsies, adult nematodes were found in the intestinal ceca. A total of 69 worms were collected, of which 64 (21 adult males and 43 adult females) were intact, and 5 showed fragmented bodies. Nematodes were washed in saline, and morphologically identified as Trichuris sp. according to Jenkins (1970) [14] and Ooi et al. (1993) [15], and then fixed in $70 \%$ ethanol until molecular analyses.

A body portion was used for molecular analyses for a subset of worms, randomly selected from the two hosts. Total genomic DNA was isolated using the ISOLATE II Genomic DNA (Bioline, UK) and used for amplification of four genomic markers. Two mitochondrial regions, the ribosomal large subunit $16 \mathrm{~S}$ (rrnLF 5'-TAAATGGCCGTCGTAACGTGACTGT$3^{\prime}$ and rrnLR 5'-AAAGAGAATCCATTCTATCTCGCAACG-3') and a portion of the cytochrome B cytb (D769 5'-GAGTAATTTTTATAATRCGRGAAGT-3' and D770 5'-AATTTTCA GGRTCTCTRCTTCAAT- $3^{\prime}$ ), and two nuclear regions, the beta-tubulin (btubF $5^{\prime}$-TGCTTGAT GTAGTCCGCAAG- $3^{\prime}$ and btubR $5^{\prime}$-GCAAAGCCAGGCATAAAGAA- $3^{\prime}$ ), and the ribosomal 18S (18SF $5^{\prime}$-CGAACGAGACTCTGGCCTAC- ${ }^{\prime}$ and 18 SR $5^{\prime}$-CCTTGTTACGACTTTTA CTTCCTC-3') were amplified. The PCR protocols used were described by Liu et al. (2012) [16], Nissen et al. (2012) [17] and Meekums et al. (2015) [18]. All PCRs included positive and negative controls. Positive amplicons were purified using Sure Clean (Bioline, UK) and shipped to Eurofins Genomics (Germany) for sequencing.

\subsection{Sequencing, Evolutionary Distance, and Phylogenetic Analyses}

Good quality sequences were used for genetic variability estimations and comparisons with previously collected data from specimens of Trichuris sp. infecting in different years the Japanese Macaques living in the same premises [10,11], with the aim to infer the possible route of infection and persistence in the captive macaques of the Bioparco. In these groups of specimens, we estimated within and between group genetic distances (using the $p$-distance method). Moreover, for comparative phylogenetic purposes, Trichuris sp. representative of branches belonging to the evolutionary Clade 2 defined by Cavallero et al. (2019) [11] were also included. The Clade 2 includes T. trichiura infecting humans and other primates and other Trichuris spp. showing affiliation for particular NHP species. One 
dataset was created for each region analyzed, and alignments were tested with ModelTest (implemented in MEGA7) to compare the fit of nucleotide substitution models, according to the lowest Bayesian information criterion (BIC) score $[19,20]$. Phylogenetic trees were obtained using the Maximum Likelihood (ML) statistical method and 1000 bootstrap pseudoreplications using MEGA7 software [20]. For the datasets' details, see Tables 1 and 2.

Table 1. Materials analyzed in the present study for phylogenetic inferences based on two mitochondrial markers (16S and $c y t b)$. In bold is the material analyzed here.

\begin{tabular}{|c|c|c|c|c|}
\hline Parasite Species & Host Species & GenBank Accession Number & Specimen Code & Authors and References \\
\hline \multicolumn{5}{|c|}{ Dataset_16S } \\
\hline T. trichiura & Homo sapiens & $\begin{array}{c}\text { GU385218 } \\
\text { AM993017-18 }\end{array}$ & $\begin{array}{c}\mathrm{H} 1 \\
\mathrm{H} 2-3\end{array}$ & Liu et al. (2012) [16] \\
\hline T. trichiura & Homo sapiens & KP781898-KP781901 & H8-11 & Meekums et al. (2015) [10] \\
\hline T. trichiura & Homo sapiens & KU524541-43 & $\mathrm{H} 22-24$ & Hawash et al. (2016) [21] \\
\hline Trichuris sp. & Macaca fuscata & MW403712-16 & $\begin{array}{c}\text { TRMF4, } 34,48,61,72 \\
\text { plus } 8 \text { undeposited * } \\
\text { Mfa3,5 }\end{array}$ & $\begin{array}{l}\text { Present study } \\
\text { (representative specimens) }\end{array}$ \\
\hline Trichuris sp. & Macaca fuscata & MN088542-43MN088544-58 & $\begin{array}{l}\text { Mfb2-4,6-8, } \\
10-14,16-19\end{array}$ & Cavallero et al. (2019) [11] \\
\hline Trichuris sp. & Papio sp. & KU524558-60 & P1-3 & Hawash et al. (2016) [21] \\
\hline Trichuris sp. & $\begin{array}{c}\text { Papio } \\
\text { hamadryas }\end{array}$ & MN088578-82 & Ph92-96 & Cavallero et al. (2019) [11] \\
\hline Trichuris sp. & $\begin{array}{l}\text { Chlorocebus } \\
\text { sabaeus }\end{array}$ & KU524595-97 & $\mathrm{C} 1-3$ & Hawash et al. (2016) [21] \\
\hline Trichuris sp. & $\begin{array}{l}\text { Trachypithecus } \\
\text { francoisi }\end{array}$ & KC481232-35 & TF $1-4$ & Liu et al. (2013) [22] \\
\hline \multicolumn{5}{|c|}{ Dataset_cytb } \\
\hline T. trichiura & Homo sapiens & GU385218 & $\mathrm{H} 1$ & Liu et al. (2012) [16] \\
\hline T. trichiura & Homo sapiens & KT449826 & $\mathrm{H} 4$ & Hawash et al. (2015) [23] \\
\hline T. colobae & $\begin{array}{l}\text { Colobus } \\
\text { guereza }\end{array}$ & LM994704 & $\operatorname{Cg} 1$ & Callejón et al. (2015) [24] \\
\hline Trichuris sp. & Macaca fuscata & MW403707-11 & $\begin{array}{l}\text { TRMF } 4,34,44,58,61 \\
\text { plus } 6 \text { undeposited }\end{array}$ & $\begin{array}{l}\text { Present study (representative } \\
\text { specimens) }\end{array}$ \\
\hline Trichuris sp. & Macaca fuscata & MK914550-53МK914554-61 & $\begin{array}{c}\text { Mfa3-5 } \\
\text { Mfb2-4,7,10-13 }\end{array}$ & Cavallero et al. (2019) [11] \\
\hline T. ursinus & Papio ursinus & LT627357-60 & PU1-4 & Rivero et al. (2020) [25] \\
\hline Trichuris sp. & $\begin{array}{c}\text { Papio } \\
\text { hamadryas }\end{array}$ & KT449824 & P4 & Hawash et al. (2015) [23] \\
\hline Trichuris sp. & $\begin{array}{l}\text { Papio } \\
\text { hamadryas }\end{array}$ & MK914573-77 & Ph91-95 & Cavallero et al. (2019) [11] \\
\hline Trichuris sp. & Papio anubis & KT449825 & P5 & Hawash et al. (2015) [23] \\
\hline Trichuris sp. & Papio sp. & LM994703 & P6 & Callejón et al. (2015) [24] \\
\hline \multicolumn{5}{|c|}{ Outgroup species } \\
\hline Trichinella britovi & & KM357413 & & Mohandas et al. (2014) [26] \\
\hline Trichinella spiralis & & AF293969 & & Lavrov and Brown (2001) [27] \\
\hline
\end{tabular}

* each specimen is labeled according to TRMF code as for TR = Trichuris and MF = Macaca fuscata, followed by the number of isolate.

Table 2. Materials analyzed in the present study for phylogenetic inferences based on two nuclear markers (beta tubulin and ribosomal 18S). In bold is the material analyzed here.

\begin{tabular}{ccccc}
\hline Parasite Species & Host Species & GenBank Accession Number & Specimen Code & Authors \\
\hline & & \multicolumn{3}{c}{ Dataset_ßtub } \\
\hline T. trichiura & Homo sapiens & AF034219 & H4 & Bennett et al. (1999) [28] \\
T. trichiura & Homo sapiens & KF410623-24 & H5-H6 & Hansen et al. (Unpublished) [29] \\
Trichuris sp. & Papio hamadryas & KF410632-34 & P7-P9 & Hansen et al. (Unpublished) [29] \\
Trichuris sp. & Macaca fuscata & MW403705-06 & TRMF4,48 plus 10 & Present study (representative specimens) \\
\hline
\end{tabular}


Table 2. Cont.

\begin{tabular}{|c|c|c|c|c|}
\hline Parasite Species & Host Species & GenBank Accession Number & Specimen Code & Authors \\
\hline \multicolumn{5}{|c|}{ Outgroup species } \\
\hline Trichinella spiralis & $\begin{array}{c}\text { Rattus } \\
\text { norvegicus }\end{array}$ & XM_003369432 & Tspi & Mitreva et al. (2011) [30] \\
\hline \multicolumn{5}{|c|}{ Dataset_18S } \\
\hline T. trichiura & Macaca fuscata & AB699092 & TtMF1 & Arizono et al. (2012) [31] \\
\hline Trichuris sp. & Macaca fuscata & MW396470-71 & $\begin{array}{l}\text { TRMF4,6 plus } 10 \\
\text { undeposited * }\end{array}$ & Present study (representative specimens) \\
\hline T. trichiura & Homo sapiens & AB699090 & TtHS1 & Arizono et al. (2012) [31] \\
\hline T. trichiura & Homo sapiens & GQ352553 & TH1 & Putaporntip et al. (2010) [32] \\
\hline T. trichiura & Homo sapiens & MF288632 & $\mathrm{TZY}$ & Phosuk et al. (2017) [33] \\
\hline \multicolumn{5}{|c|}{ Outgroup species } \\
\hline Trichinella spiralis & Sus scrofa & AY497012 & Tspi & Li et al. (Unpublished) [34] \\
\hline
\end{tabular}

* each specimen is labeled according to TRMF code as for TR = Trichuris and MF = Macaca fuscata, followed by the number of isolate.

\section{Results}

\section{Molecular and Phylogenetic Analyses}

Thirteen good quality sequences were obtained for Dataset_16S, eleven for Dataset_cytb, twelve for Dataset_18S and twelve for Dataset_ßtub. All samples showed high genetic homogeneity.

The Dataset_16S included 50 specimens for a total length of $395 \mathrm{bp}$ and the evolutionary model selected was Kimura-2 parameter + Invariant sites. The tree with the highest log-likelihood (Figure 1) described two main branches and four groups inside the Clade 2 (according to Cavallero et al. 2019 [11]). The first main branch is supported by a high bootstrap value (97\%) and includes the subclade MF (bootstrap 91\%) with the specimens analyzed here, and Trichuris from M. fuscata previously collected from Bioparco (Mfb specimens). The group is related with $T$. trichiura from humans (subclade $H$ ) in a branch with $78 \%$ of the statistical support. Few Trichuris from $M$. fuscata previously collected at the Bioparco (Mfa specimens) clustered into the Clade 2A with Trichuris from other primates as Papio hamadryas, Chlorocebus sabaeus, and humans (95\% bootstrap). The last group was represented by the sister branch of Trichuris infecting Trachypithecus francoisi.

The alignment of Dataset_cytb included 40 specimens for a total length of $477 \mathrm{bp}$, with the best fit model of Kimura-2 parameter + Invariant sites. The ML tree showed the same topology described for $16 S$ tree, with two main branches and four groups, with slight differences in evolutionary relationships (Figure 2). The first main branch is supported by the highest bootstrap value $(100 \%)$ and it includes three branches: one branch with T. trichiura from humans and Trichuris sp. from Papio anubis (97\%), and a second branch (73\%) with one group (98\%) including all the specimens here analyzed and Trichuris from M. fuscata previously collected from Bioparco (Mfb specimens). A third group including $T$. trichiura from humans, Trichuris from $M$. fuscata previously collected at the Bioparco (Mfa specimens) and Trichuris from baboons. The last branch grouped Trichuris sp. from Colobus guereza and Papio (98\%). Within mean group's distance showed the following values: Mfa (0.001); Mfb (0.008), and TRMF (0.010). Between groups distance showed a very low p-distance between TRMF and Mfb (1.1\%) and similar distance between TRMF/Mfa and $\mathrm{Mfa} / \mathrm{Mfb}$ (13.1\% and $13.3 \%$, respectively). 


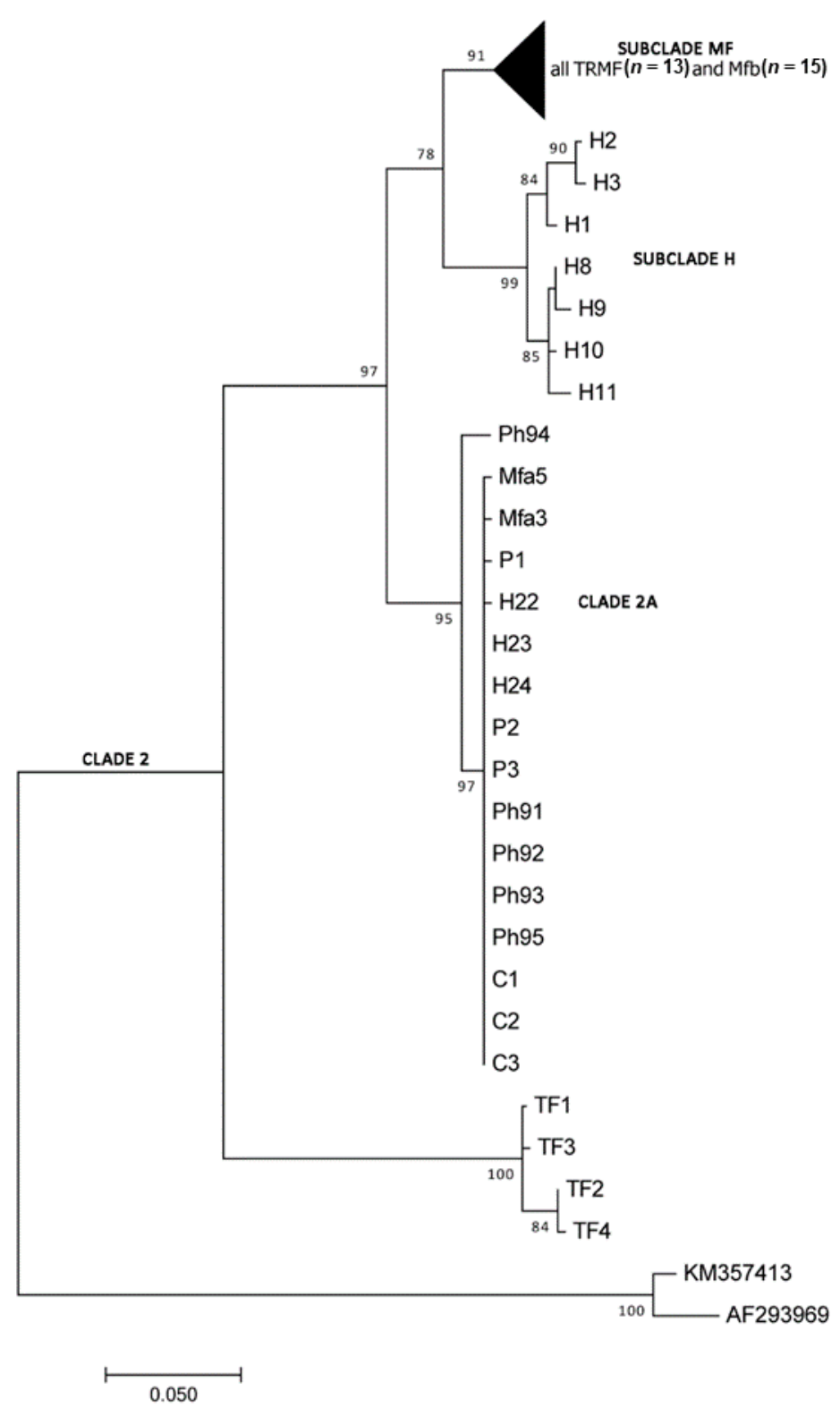

Figure 1. Maximum Likelihood (ML) tree elaborated from the Dataset_16S showing the evolutionary relationships of Trichuris spp. included (see Table 1). Bootstrap values are reported at nodes and affiliation to clades is indicated on the right.

The alignment of Dataset_18S included 15 specimens for a total length of $426 \mathrm{bp}$, with the best-fit model Kimura 2 parameter. All the specimens here collected form a unique clade with the two available T. trichiura sequences. Similarly, the alignment of Dataset_ßtub included 19 specimens for a total length of $390 \mathrm{bp}$, with the best fit model Kimura 2 parameter, and showed a unique clade with all the specimens and T. trichiura from humans and Trichuris sp. from baboons. However, poor statistical support was observed at internal subclading, as reported in the consensus trees (Supplementary Figure S1).

Sequences for representative specimens for each molecular marker were submitted to GenBank (accession numbers indicated in Tables 1 and 2). 


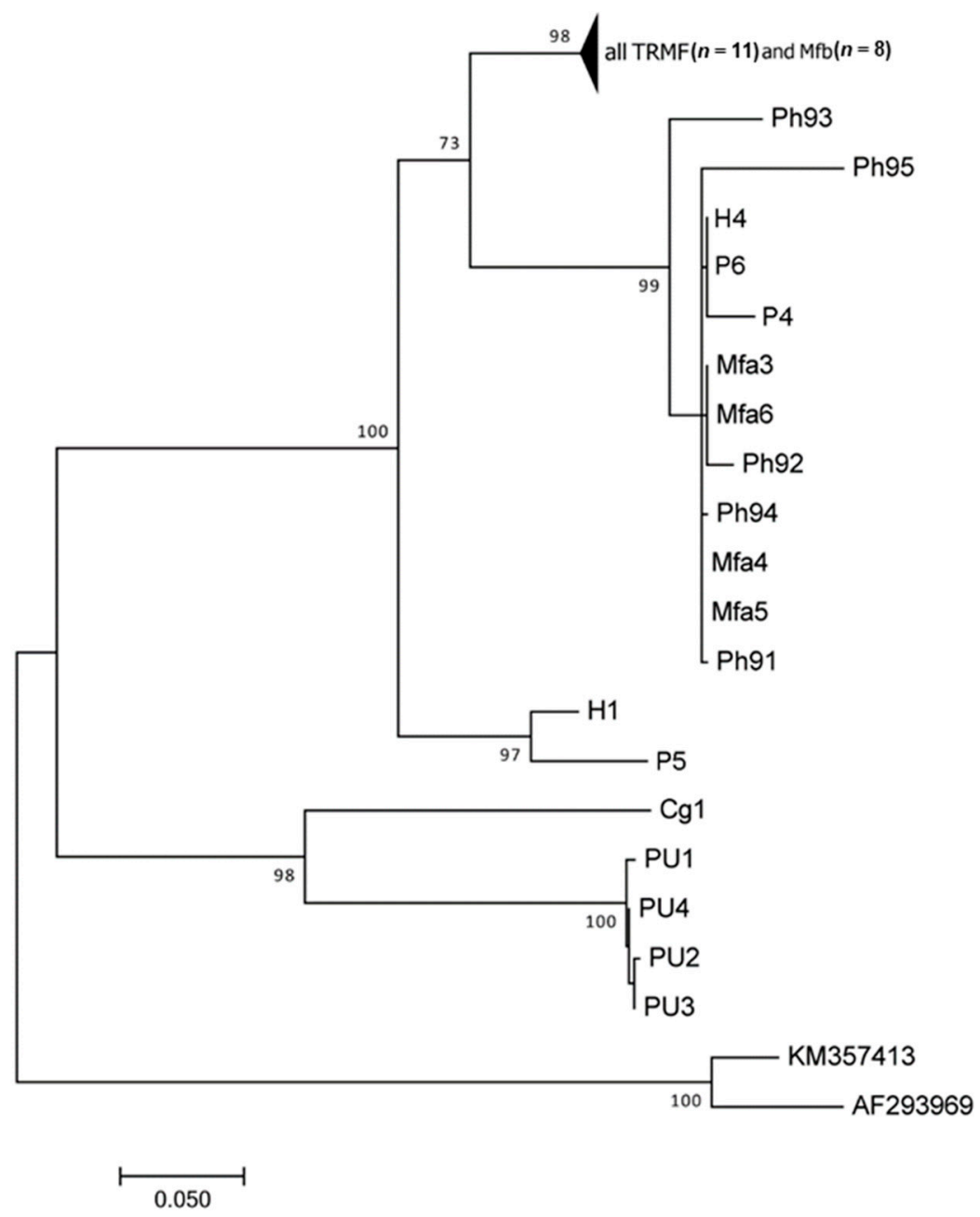

Figure 2. ML tree elaborated from the Dataset_cytb showing the evolutionary relationships of Trichuris spp. included (see Table 1). Bootstrap values are reported at nodes.

\section{Discussion}

In this study, molecular tools were used to identify and characterize at genetic level Trichuris worms isolated from two Japanese macaques living in the Bioparco Zoological Garden of Rome through sequencing of nuclear and mitochondrial regions. Molecular markers as $c y t b$ and $16 \mathrm{~S}$ were already used in previous analyses to characterize at the molecular level Trichuris sp. infecting Japanese macaques [11], while nuclear regions betatubulin and ribosomal subunit $18 \mathrm{~S}$ were used to characterize specimens collected in the present work for the first time to add information on more conserved and evolutionary stable regions and to allow comparisons, according to the availability of sequences in public repositories.

The use of a molecular approach is highly recommended for species assignment, and the combination of multiple markers is useful to increase the resolution power of population genetics and phylogenetic analyses [24]. The taxonomic identity and systematics of $T$. trichiura was recently debated and several studies demonstrated the existence of more than one taxonomic entity infecting primate species, with no clear definition of species boundaries and, consequently, of zoonotic potential [8,11,23,35].

At the genetic level, all specimens collected here were very similar to each other, and one (Mfb specimens) of the two groups of previously collected Trichuris sp. from the same host species living in the premises in 2015-19. Specimens belonging to Mfa and $\mathrm{Mfb}$ were differentiated by more than fifty single nucleotide polymorphism (SNPs) at the cox1 analysis [13]. Based on mitochondrial markers, the level of intraspecific variation 
indicates the presence of a uniform population. This is even more evident in the nuclear markers, showing a limited number of SNPs (five SNPs over $390 \mathrm{bp}$ in beta-tubulin and four SNPs over $426 \mathrm{bp}$ in $18 \mathrm{~S}$ region). This homogeneous taxonomic unit appears to be different from the second group (Mfa specimens) including a few specimens of Trichuris sp. previously collected from the same host species, more closely related to T. trichiura species infecting human. However, the zoonotic potential of the specimens analyzed here cannot be completely excluded. Moreover, all of these specimens belong to the Clade 2, which includes all of the putative members of the T. trichiura complex.

According to the last inventory of primates hosted at Bioparco (January 2020), four large areas with external and internal spaces are dedicated to stable and endangered primates. One exhibit includes orangutans (Pongo pygmaeus), one includes small monkeys as the emperor and the cotton-top tamarins (Saguinus imperator and Saguinus oedipus, respectively) and the pygmy marmoset (Callithrix pygmaea), another is for the chimpanzees (Pan troglodytes), and the last one includes the ring tailed lemurs (Lemur catta). Additional small areas host the collared mangabeys (Cercocebus torquatus), the capuchin monkeys (Sapajus sp.) and the mandrill (Mandrillus sphinx). With the exception of orangutans and chimpanzees, all the other primates' premises are in the same side of the Bioparco. The distribution of premises should be accounted for a proper evaluation of transmission patterns of pathogens. In fact, the possibility of events of cross infection between premises and primates were already reported in the Bioparco between Lemur catta and Macaca fuscata [13].

Trichuris has been observed to infect $M$. fuscata hosted in the Bioparco for over a decade. Besides the pens' flooring and the structure of the exhibit, a possible explanation for the persistence of such infections in the premises can be related also to the administration of pharmacological therapies with food, given the context of hierarchical competition. In fact, access to food could be influenced by social dynamics of primates, and the dominant animals may eat more food than others, thus limiting the efficacy of pharmacological treatments.

In conclusion, this study gives further evidence that, although more than one Trichuris sp. taxon is able to infect primates, a strong host affiliation/specificity appears characteristic of specimens infecting $M$. fuscata. However, as the number of specimens analyzed from captive primates, including Japanese macaques, are still scarce and this is even poorer from wild specimens, the present results highlight the need for further data to infer the taxonomy of Trichuris sp. from primates with due accuracy.

Supplementary Materials: The following are available online at https:/ / www.mdpi.com/2075-172 9/11/1/18/s1, Figure S1: ML trees elaborated from the Dataset_18S (a) and the Dataset_btub (b) showing the evolutionary relationships of Trichuris spp. included (see Table 2). Bootstrap values are reported at nodes.

Author Contributions: K.G.F. and C.D.L. inspected dead macaques and provided the material, giving substantial contribution to the acquisition of data; S.C. performed the experiments and provided data analysis; M.M.D.F. submitted material to GenBank and supported data analyses. S.C., S.R., F.B. and S.D. wrote the manuscript giving substantial contribution to the interpretation of data. All authors have read and agreed to the published version of the manuscript.

Funding: This research was funded by Sapienza University of Rome, through the Sapienza Starting Grant 2020 awarded to SR (protocol number AR120172A8FD7E2B).

Institutional Review Board Statement: Not applicable.

Informed Consent Statement: Not applicable.

Acknowledgments: Authors are very grateful for the suggestions of Michele Capasso.

Conflicts of Interest: The authors declare no conflict of interest. 


\section{References}

1. Levecke, B.; Dorny, P.; Geurden, T.; Vercammen, F.; Vercruysse, J. Gastrointestinal protozoa in non-human primates of four zoological gardens in Belgium. Vet. Parasitol. 2007, 148, 236-246. [CrossRef]

2. Calle, P.; Joslin, J. New world and old world monkeys. In Zoo and Wild Animal Medicine; Fowler, M., Miller, R., Eds.; Elsevier Saunders: St. Louis, MO, USA, 2014; pp. 301-335.

3. Aviruppola, A.J.M.K.; Rajapakse, R.P.V.J.; Rajakaruna, R.S. Coprological survey of gastrointestinal parasites of mammals in Dehiwala National Zoological Gardens, Sri Lanka. Ceylon J. Sci. 2016, 45, 83. [CrossRef]

4. Da Silva Barbosa, A.; Pinheiro, J.L.; dos Santos, C.R.; de Lima, C.S.C.C.; Dib, L.V.; Echarte, G.V.; Augusto, A.M.; Bastos, A.C.M.P.; Antunes Uchôa, C.M.; Bastos, O.M.P.; et al. Gastrointestinal parasites in captive animals at the Rio de Janeiro zoo. Acta Parasitol. 2020, 65, 237-249. [CrossRef]

5. Li, M.; Zhao, B.; Li, B.; Wang, Q.; Niu, L.; Deng, J.; Gu, X.; Peng, X.; Wang, T.; Yang, G. Prevalence of gastrointestinal parasites in captive non-human primates of twenty-four zoological gardens in China. J. Med. Primatol. 2015, 44, 168-173. [CrossRef]

6. Yamaguti, S. The nematodes of Vertebrates. In Systema Helminthum; Interscience (Wiley): New York, NY, USA, 1962.

7. Bethony, J.; Brooker, S.; Albonico, M.; Geiger, S.M.; Loukas, A.; Diemert, D.; Hotez, P.J. Soil-Transmitted helminth infections: Ascariasis, trichuriasis, and hookworm. Lancet 2006, 367, 1521-1532. [CrossRef]

8. Ravasi, D.F.; O'Riain, M.J.; Davids, F.; Illing, N. Phylogenetic evidence that two distinct Trichuris genotypes infect both humans and non-human primates. PLoS ONE 2012, 7, e44187. [CrossRef]

9. Zanzani, S.A.; Gazzonis, A.L.; Epis, S.; Manfredi, M.T. Study of the gastrointestinal parasitic fauna of captive non-human primates (Macaca fascicularis). Parasitol. Res. 2016, 115, 307-312. [CrossRef]

10. Cavallero, S.; De Liberato, C.; Friedrich, K.G.; Di Cave, D.; Masella, V.; D’Amelio, S.; Berrilli, F. Genetic heterogeneity and phylogeny of Trichuris spp. from captive non-human primates based on ribosomal DNA sequence data. Infect. Genet. Evol. 2015, 34, 450-456. [CrossRef]

11. Cavallero, S.; Nejsum, P.; Cutillas, C.; Callejón, R.; Doležalová, J.; Modrý, D.; D’Amelio, S. Insights into the molecular systematics of Trichuris infecting captive primates based on mitochondrial DNA analysis. Vet. Parasitol. 2019, 272, 23-30. [CrossRef]

12. Reichard, M.V.; Wolf, R.F.; Carey, D.W.; Garrett, J.J.; Briscoe, H.A. Efficacy of fenbendazole and milbemycin oxime for treating baboons (Papio cynocephalus anubis) infected with Trichuris trichiura. J. Am. Assoc. Lab. Anim. Sci. 2007, 46, 42-45.

13. Montalbano Di Filippo, M.; Berrilli, F.; De Liberato, C.; Di Giovanni, V.; D’Amelio, S.; Friedrich, K.G.; Cavallero, S. Molecular characterization of Trichuris spp. from captive animals based on mitochondrial markers. Parasitol. Int. 2020, 75. [CrossRef]

14. Jenkins, T.A. Morphological and histochemical study of Trichuris suis (Schrank, 1788) with special reference to the host-parasite relationship. Parasitology 1970, 61, 357-374. [CrossRef]

15. Ooi, H.; Tenora, F.; Itoh, K.; Kamiya, M. Comparative study of Trichuris trichiura from non-human primates and from man, and their difference with T. suis. J. Vet. Med. Sci. 1993, 55, 363-366. [CrossRef]

16. Liu, G.H.; Gasser, R.B.; Su, A.; Nejsum, P.; Peng, L.; Lin, R.Q.; Li, M.W.; Xu, M.J.; Zhu, X.Q. Clear genetic distinctiveness between human- and pig-derived Trichuris based on analyses of mitochondrial datasets. PLoS Negl. Trop. Dis. 2012, 6, e1539. [CrossRef]

17. Nissen, S.; Al-Jubury, A.; Hansen, T.V.A.; Olsen, A.; Christensen, H.; Thamsborg, S.M.; Nejsum, P. Genetic analysis of Trichuris suis and Trichuris trichiura recovered from humans and pigs in a sympatric setting in Uganda. Vet. Parasitol. 2012, 188, 68-77. [CrossRef]

18. Meekums, H.; Hawash, M.B.; Sparks, A.M.; Oviedo, Y.; Sandoval, C.; Chico, M.E.; Stothard, J.R.; Cooper, P.J.; Nejsum, P.; Betson, M.A. Genetic analysis of Trichuris trichiura and Trichuris suis from Ecuador. Parasites Vectors 2015, 8, 1-5. [CrossRef]

19. Nei, M.; Kumar, S. Molecular Evolution and Phylogenetics; Oxford University Press: New York, NY, USA, 2000.

20. Kumar, S.; Stecher, G.; Tamura, K. MEGA7: Molecular evolutionary genetics analysis version 7.0 for bigger datasets. Mol. Biol. Evol. 2016, 33, 1870-1874. [CrossRef]

21. Hawash, M.; Betson, M.; Al-Jubury, A.; Ketzis, J.; LeeWillingham, A.; Bertelsen, M.; Cooper, P.; Littlewood, D.; Zhu, X.; Nejsum, P. Whipworms in humans and pigs: Origins and demography. Parasites Vectors 2016, 9. [CrossRef]

22. Liu, G.; Gasser, R.; Nejsum, P.; Wang, Y.; Chen, Q.; Song, H.; Zhu, X. Mitochondrial and nuclear ribosomal DNA evidence supports the existence of a new Trichuris species in the endangered francois' leaf-monkey. PLoS ONE 2013, 8, e66249. [CrossRef]

23. Hawash, M.B.F.; Andersen, L.O.; Gasser, R.B.; Stensvold, C.R.; Nejsum, P. Mitochondrial genome analyses suggest multiple Trichuris species in humans, baboons, and pigs from different geographical regions. PLoS Negl. Trop. Dis. 2015, 9, e0004059. [CrossRef]

24. Callejón, R.; Cutillas, C.; Nadler, S. Nuclear and mitochondrial genes for inferring Trichuris phylogeny. Parasitol. Res. 2015, 114, 4591-4599. [CrossRef]

25. Rivero, J.; García-Sánchez, Á.M.; Zurita, A.; Cutillas, C.; Callejón, R. Trichuris trichiura isolated from Macaca sylvanus: Morphological, biometrical, and molecular study. BMC Vet. Res. 2020, 16, 445. [CrossRef]

26. Mohandas, N.; Pozio, E.; La Rosa, G.; Korhonen, P.; Young, N.; Koehler, A.; Hall, R.; Sternberg, P.; Boag, P.; Jex, A.; et al. Mitochondrial genomes of Trichinella species and genotypes-A basis for diagnosis, and systematic and epidemiological explorations. Int. J. Parasitol. 2014, 44, 1073-1080. [CrossRef]

27. Lavrov, D.; Brown, W. Trichinella spiralis mtDNA: A nematode mitochondrial genome that encodes a putative ATP8 and normally structured tRNAS and has a gene arrangement relatable to those of coelomate metazoans. Genetics 2001, 157, $621-637$.

28. Bennet, A.; Barker, G.; Bundy, D.A. Beta-Tubulin gene from Trichuris trichiura. Mol. Biochem. Parasitol. 1999, 103, 111-116. 
29. Hansen, T.; Thamsborg, S.; Olsen, A.; Nejsum, P. Genetic variations in the beta-tubulin gene and the internal transcribed spacer (ITS-2) region of Trichuris species from man and baboons. Parasites Vectors 2013, 236. [CrossRef]

30. Mitreva, M.; Jasmer, D.P.; Zarlenga, D.S.; Wang, Z.; Abubucker, S.; Martin, J.; Taylor, C.M.; Yin, Y.; Fulton, L.; Minx, P.; et al. The draft genome of the parasitic nematode Trichinella spiralis. Nat. Genet. 2011, 43, 228-235. [CrossRef]

31. Arizono, N.; Yamada, M.; Tegoshi, T.; Onishi, K. Molecular identification of Oesophagostomum and Trichuris eggs isolated from wild Japanese macaques. Korean J. Parasitol. 2012, 50, 253-257. [CrossRef]

32. Putaporntip, C.; Jongwutiwes, S. Detection of Trichuris trichiura and T. vulpis in human and dog stool samples by nested PCR. Asian Biomed. 2010, 4. [CrossRef]

33. Phosuk, I.; Sanpool, O.; Thanchomnang, T.; Sadaow, L.; Rodpai, R.; Anamnart, W.; Janwan, P.; Wijit, A.; Laymanivong, S.; Aung, W.; et al. Molecular identification of Trichuris suis and Trichuris trichiura eggs in human populations from Thailand, Lao PDR, and Myanmar. Am. J. Trop. Med. Hyg. 2018, 98, 39-44. [CrossRef]

34. Li, D.; Wang, X.; Song, M. Cloning and Sequence Analysis of the 18S Ribosomal RNA Gene from Five Isolates of Trichinella. Unpublished. Available online: https:/ / www.ncbi.nlm.nih.gov/nuccore/AY497012 (accessed on 30 December 2020).

35. Doležalová, J.; Oborník, M.; Hajdušková, E.; Jirku, M.; Petrželková, K.J.; Bolechová, P.; Cutillas, C.; Callejón, R.; Jaroš, J.; Beránková, Z.; et al. How many species of whipworms do we share? Whipworms from man and other primates form two phylogenetic lineages. Folia Parasitol. 2015, 62, 1-12. [CrossRef] 